\title{
Catalytic self-sustained combustion of toluene and reaction pathway over $\mathrm{Cu}_{\mathrm{x}} \mathrm{Mn}_{1-\mathrm{x}} \mathrm{Ce}_{0.75} \mathrm{Zr}_{0.25} / \mathrm{TiO}_{2}$ catalysts
}

\author{
Chenchen Zhao ${ }^{\mathrm{a}}$, Qinglan Hao ${ }^{\mathrm{a}}$, Qing Zhang ${ }^{\mathrm{a}}$, Ningna Yan ${ }^{\mathrm{a}}$, Jiaren Liu ${ }^{\mathrm{a}}$, Baojuan Dou ${ }^{\mathrm{a}, *}$, \\ Feng Bin ${ }^{\mathrm{b}, *}$ \\ a Tianjin University of Science \& Technology, Tianjin 300457, China \\ ${ }^{\mathrm{b}}$ Institute of Mechanics, Chinese Academy of Science, Beijing 100190, China
}

\section{A R T I C L E I N F O}

\section{Keywords:}

Toluene

Self-sustained combustion

Ce-Zr based catalyst

Lean-combustion limit

Reaction pathway

\begin{abstract}
A B S T R A C T
The catalytic self-sustained combustion of toluene over $\mathrm{Cu}_{\mathrm{x}} \mathrm{Mn}_{1-\mathrm{x}} \mathrm{Ce}_{0.75} \mathrm{Zr}_{0.25} / \mathrm{TiO}_{2}$ catalysts $(x=1,0.5,0)$ was studied in a microscale combustor. The catalytic activity is determined not only by the temperature with toluene conversion of $90 \%\left(T_{\text {co }}\right)$, but also by the corresponding lean-combustion limits. It was found that the self-sustained combustion was achieved successfully over the catalysts, with the toluene concentrations of 0.35 con.\%,

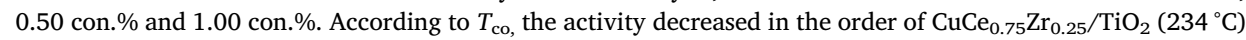
$>\mathrm{Cu}_{0.5} \mathrm{Mn}_{0.5} \mathrm{Ce}_{0.75} \mathrm{Zr}_{0.25} / \mathrm{TiO}_{2}\left(238^{\circ} \mathrm{C}\right)>\mathrm{MnCe}_{0.75} \mathrm{Zr}_{0.25} / \mathrm{TiO}_{2}\left(284{ }^{\circ} \mathrm{C}\right)$. The excellent activity of $\mathrm{CuCe}_{0.75} \mathrm{Zr}_{0.25} /$ $\mathrm{TiO}_{2}$ catalyst could be ascribed to the high content of active lattice oxygen, good low-temperature reducibility and homogeneous dispersion, combined with the results of $\mathrm{H}_{2}$-TPR, $\mathrm{O}_{2}$-TPD and XPS. Furthermore, the results of in-situ DRIFT and temperature-programmed oxidation (TPO) of toluene in $\mathrm{N}_{2}$ atmosphere suggested that toluene was adsorbed on the catalyst surface by removing $\alpha-\mathrm{H}$ from methyl and combining with active oxygen specie to form benzyl group, which was finally oxidized into $\mathrm{CO}_{2}$ and $\mathrm{H}_{2} \mathrm{O}$ with lattice oxygen.
\end{abstract}

\section{Introduction}

Toluene is one of the major contributors to VOCs which are mainly released by industries processes. It is hazardous to environment and even carcinogenic for both human and animal [1]. Abundant global technologies based on recovery and destruction have been developed to meet the strict environment regulations of toluene emission limitation.

To accelerate the miniaturization of energy systems and increase the reaction rate, the catalytic combustion in microscale tube, named "catalytic self-sustained combustion", has been developed recently [2]. The technology of stabilizing combustion is an economical strategy for complete VOCs degradation without heat input. In this process, only a small amount of heat is need for the ignition, and the heat released from the reaction is enough to maintain the combustion without any other energy input [3]. Yang [2] and Scarpa [4] found that alkanes including methane, propane and $n$-octane could achieve self-sustained combustion successively over Pt-based catalyst supported ZSM-5 or $\gamma-\mathrm{Al}_{2} \mathrm{O}_{3}$ with relatively lower concentration. In addition, the self-sustained combustion can be obtained by $\mathrm{CO} \rightarrow \mathrm{CO}_{2}$ exothermic reaction over the CuCe/ZSM-5 and $\mathrm{CuCe}_{0.75} \mathrm{Zr}_{0.25} / \mathrm{TiO}_{2}$ catalysts in our previous studies $[5,6]$.
Catalytic self-sustained combustion of toluene in a small-scale combustor is flameless combustion with a small amount of fuels, which are used to generate the local hot spots on the catalyst surface, leading to the successful self-sustained combustion. The challenge of the technology is to design a proper catalyst to enhance the stability of microcombustion. Copper-based and manganese-based catalysts are considered as the excellent catalysts for VOCs removal due to their variety of electronic structures and capability of regeneration [7-11]. Copper doping could significantly enhance the catalytic activity to achieve complete VOCs degradation by extracting the lattice oxygen from $\mathrm{CuO}$ $[8,9]$. The $\mathrm{MnO}_{\mathrm{x}}$ catalysts for VOCs oxidation have been considered as the better alternative than the expensive noble metal, owing to the coexistence of mixed valance states from -3 to +7 and low toxicity $[1,10,11]$. Some investigators have tried to prepare bimetallic catalysts to study their high activity through the synergistic effect between the two phases [12-14]. For instance, Li et al. [12] found that CuMn(y)O $\mathrm{O}_{\mathrm{x}} /$ $\gamma-\mathrm{Al}_{2} \mathrm{O}_{3}$ exhibited higher catalytic activity $\left(T_{90}=229{ }^{\circ} \mathrm{C}\right)$ compared with $\mathrm{CuO}_{\mathrm{x}} / \gamma-\mathrm{Al}_{2} \mathrm{O}_{3}, \mathrm{MnO}_{\mathrm{x}} / \gamma-\mathrm{Al}_{2} \mathrm{O}_{3}$ for toluene oxidation, resulting from the formation of the $\mathrm{Cu}_{1.5} \mathrm{Mn}_{1.5} \mathrm{O}_{4}$ spinel structure in $\mathrm{CuMn}(\mathrm{y}) \mathrm{O}_{\mathrm{x}} / \gamma$ $\mathrm{Al}_{2} \mathrm{O}_{3}$ catalyst. However, the pure Cu-based or Mn-based catalysts are still away from arrival of satisfied catalytic performance to VOCs

\footnotetext{
* Corresponding authors.

E-mail addresses: bjdou@tust.edu.cn (B. Dou), binfeng@imech.ac.cn (F. Bin).
} 
combustion due to the poor oxygen storage-release capacity and instability of catalysts. $\mathrm{CeO}_{2}$ has the unique properties due to the plenty of oxygen vacancies associated with strong interactions with metals, and the adding of $\mathrm{CeO}_{2}$ can further improve the catalytic performance $[5,9,15-17]$. The thermal stability of the catalyst can be enhanced through the zirconium addition [15-17]. In our previous study, we have investigated the influence of $\mathrm{Cu} / \mathrm{Ce}$ molar ratio of $\mathrm{CuCe} / \mathrm{ZSM}-5$ catalysts [15] and the Ce/Zr molar ratio of CuCeZr/ZSM-5 catalysts [16] for the catalytic activity, respectively. And we found that the $\mathrm{CuCe}_{0.75} \mathrm{Zr}_{0.25} \mathrm{O}_{\mathrm{x}}$ mixed oxides exhibited excellent catalytic activity in the toluene catalytic oxidation owing to the formation of Cu-Ce-Zr-O solid solution, which improved the redox capability and oxygen storage capacity $[15,16]$, could be favorable for toluene self-sustained combustion.

Many studies have focused on the self-sustained combustion reaction with low-carbon organic compounds, such as $\mathrm{CO}$ and $\mathrm{C}_{\mathrm{n}} \mathrm{H}_{2 \mathrm{n}-2}$ $(n \leq 4)$, however, little statistical evidences related to catalytic selfsustained combustion of aromatic compounds have not been reported yet. In this paper, to acquire the performance of toluene self-sustained combustion over different catalysts, the lean-combustion limit of selfsustained combustion and the efficiency of toluene degradation were studied. $\mathrm{Cu}_{\mathrm{x}} \mathrm{Mn}_{1-\mathrm{x}} \mathrm{Ce}_{0.75} \mathrm{Zr}_{0.25} / \mathrm{TiO}_{2}$ catalysts $(x=1,0.5,0)$ were prepared by the impregnation method, and the physical and structural properties were characterized by $\mathrm{H}_{2}$-TPR, $\mathrm{O}_{2}$-TPD and XPS. Furthermore, the in-situ DRIFT experiment was carried out to discuss the possible reaction pathways for toluene catalytic combustion, and the role of lattice oxygen was also proposed based on the results of programmed-temperature oxidation in $\mathrm{N}_{2}$ atmosphere.

\section{Experimental specifications}

\subsection{Catalyst preparation}

A series of $\mathrm{Cu}_{\mathrm{x}} \mathrm{Mn}_{1-\mathrm{x}} \mathrm{Ce}_{0.75} \mathrm{Zr}_{0.25} / \mathrm{TiO}_{2}$ catalysts $(x=1,0.5,0)$ with 4.0 wt.\% $\mathrm{Cu}_{\mathrm{x}} \mathrm{Mn}_{1-\mathrm{x}} \mathrm{O}_{\mathrm{y}}$ supported on $\mathrm{TiO}_{2}$ (supplied by the Evonik Industries AG), were prepared by the incipient impregnation method. The appropriate amount of $\mathrm{Cu}\left(\mathrm{NO}_{3}\right)_{2} \cdot \mathrm{xH}_{2} \mathrm{O}, \mathrm{Mn}\left(\mathrm{NO}_{3}\right)_{2} \cdot 2 \mathrm{H}_{2} \mathrm{O}$, Ce $\left(\mathrm{NO}_{3}\right)_{3} \cdot 6 \mathrm{H}_{2} \mathrm{O}$ and $\mathrm{Zr}\left(\mathrm{NO}_{3}\right)_{4} \cdot 5 \mathrm{H}_{2} \mathrm{O}$ were well dissolved in deionized water before being added dropwise to nanometer titanium dioxide. The resulting emulsions were dried at room temperature until complete evaporation of the water, then staved at $105^{\circ} \mathrm{C}$ for $12 \mathrm{~h}$ and calcined in air at $550{ }^{\circ} \mathrm{C}$ for $4 \mathrm{~h}$. The molar ratio of $\mathrm{Cu}_{\mathrm{x}} \mathrm{Mn}_{1-\mathrm{x}}$ : Ce: $\mathrm{Zr}$ was 4: $3: 1$, and the $\mathrm{Cu}_{\mathrm{x}} \mathrm{Mn}_{1-\mathrm{x}}:(\mathrm{Ce}+\mathrm{Zr})$ ratio was $1: 1$, which are the optimal ratio from our previous works $[15,16]$.

Finally, all the catalysts were sieved in a size of 20-30 meshes for testing. The obtained catalysts were named as $\mathrm{CuCe}_{0.75} \mathrm{Zr}_{0.25} / \mathrm{TiO}_{2}$ (CuCZ/T), $\quad \mathrm{Cu}_{0.5} \mathrm{Mn}_{0.5} \mathrm{Ce}_{0.75} \mathrm{Zr}_{0.25} / \mathrm{TiO}_{2} \quad(\mathrm{CuMnCZ} / \mathrm{T}) \quad$ and $\mathrm{MnCe}_{0.75} \mathrm{Zr}_{0.25} / \mathrm{TiO}_{2}(\mathrm{MnCZ} / \mathrm{T})$.

\subsection{Catalyst characterization}

The Powder X-ray diffraction (XRD) data was performed on XRD6100 (Shimadzu, Japan) equipped with X-ray diffractometer using Cu$\mathrm{K} \alpha(\lambda=1.540 \AA, 40 \mathrm{kV})$. The measurements were conducted in the $2 \Theta$ range from $5^{\circ}$ to $80^{\circ}$ with a scanning rate of $2^{\circ} / \mathrm{min}$. Hydrogen temperature programmed reduction $\left(\mathrm{H}_{2}\right.$-TPR) was measured with a PCA140 instrument (Bolider). To eliminate contaminants, $200 \mathrm{mg}$ sample was pretreated at $500{ }^{\circ} \mathrm{C}$ for $1 \mathrm{~h}$ in argon $(50 \mathrm{~mL} / \mathrm{min})$. After the temperature was cooled to $50^{\circ} \mathrm{C}$, the TPR analysis were performed in 5 vol. $\% \mathrm{H}_{2} / \mathrm{Ar}(50 \mathrm{~mL} / \mathrm{min})$ at the temperature programmed $\left(10^{\circ} \mathrm{C} / \mathrm{min}\right)$ in the range of $50-800{ }^{\circ} \mathrm{C}$. The reduction degree $\left(\mathrm{R}_{\mathrm{d}}\right)$ of the catalysts was calculated by the ratio of the hydrogen consumption of $\mathrm{CuMnO}_{\mathrm{x}}$ and theoretical content (4\%) in the catalysts. Temperature-programmed desorption of $\mathrm{O}_{2}\left(\mathrm{O}_{2}\right.$-TPD) data was also collected with the same instrument. To remove moisture, a cold trap was introduced before the released gas entered the thermal conductivity detector (TCD). The same amount of catalyst was placed in a pure oxygen flow $(50 \mathrm{~mL} / \mathrm{min})$ for $1 \mathrm{~h}$ at $500{ }^{\circ} \mathrm{C}$. Subsequently, the catalyst was heated from room temperature to $1000{ }^{\circ} \mathrm{C}$ at a rate of $10^{\circ} \mathrm{C} / \mathrm{min}$ under the Ar atmosphere. TCD was employed to continuously monitor the consumption of oxygen. X-ray photoelectron spectra (XPS) was measured with a PerkinElmer PHI-1600 ESCA spectrometer. The X-ray source was an Mg anode target $(350 \mathrm{eV})$. The binding energy values of each species were corrected with an internal standard of $\mathrm{C} 1 \mathrm{~s}(\mathrm{~Eb}=284.8 \mathrm{eV})$.

\subsection{In-situ DRIFT}

The in-situ diffuse reflectance Fourier transform (DRIFT) result of the toluene combustion over CuCZ/T catalyst was analyzed by using a Bruker Tensor 27 spectrometer equipped with MCT detector. Prior to all measurements, the $\mathrm{CuCZ} / \mathrm{T}$ catalyst was pretreated in the high-purity $\mathrm{N}_{2}$ atmosphere $(50 \mathrm{~mL} / \mathrm{min})$ at $300{ }^{\circ} \mathrm{C}$ for $0.5 \mathrm{~h}$. The toluene gas was bubbled into the reactor by oxygen flow $(30 \mathrm{~mL} / \mathrm{min})$, and the corresponding sample spectrum was recorded until the catalyst was saturated by the toluene adsorption. DRIFTS were probed with the temperature interval of $10{ }^{\circ} \mathrm{C}$ from $50{ }^{\circ} \mathrm{C}$ to $400{ }^{\circ} \mathrm{C}$ under $\mathrm{O}_{2}$ and toluene gas.

\subsection{Catalytic activity measurement}

Toluene catalytic self-sustained combustion experiment was carried out in a micro-reactor made of quartz tube $(\varnothing=6.0 \mathrm{~mm} \times 1.0 \mathrm{~mm}$, $\mathrm{L}=200 \mathrm{~mm}$ ). The experimental set-up of toluene catalytic self-sustained combustion includes continuous flow gas supplying systems, catalytic self-sustained combustion reactor and gaseous analytical systems (Fig. 1). The flow rates of toluene and air were controlled by mass flow controllers, which are shown as MFC1 (F1) and MFC2 (F2) in Fig. 1, respectively, with a full-scale measurement accuracy of $\pm 1 \%$. The toluene concentration was controlled by adjusting the flow rate of F1 $(10 \sim 50 \mathrm{~mL} / \mathrm{min})$ and $\mathrm{F} 2(150 \sim 190 \mathrm{~mL} / \mathrm{min})$ while keeping the total flow rate constant $(200 \mathrm{~mL} / \mathrm{min})$.

The reactor filled with $200 \mathrm{mg}$ catalyst was first heated for ignition, then the heat supply was turned off to observe the combustion running auto-thermally. During the reaction process, the temperature of reactor wall was measured by using an infrared thermography (T640, FLIR, USA). The judgment of catalytic self-sustained combustion in the experiment is based on the variation of the wall temperature, which is

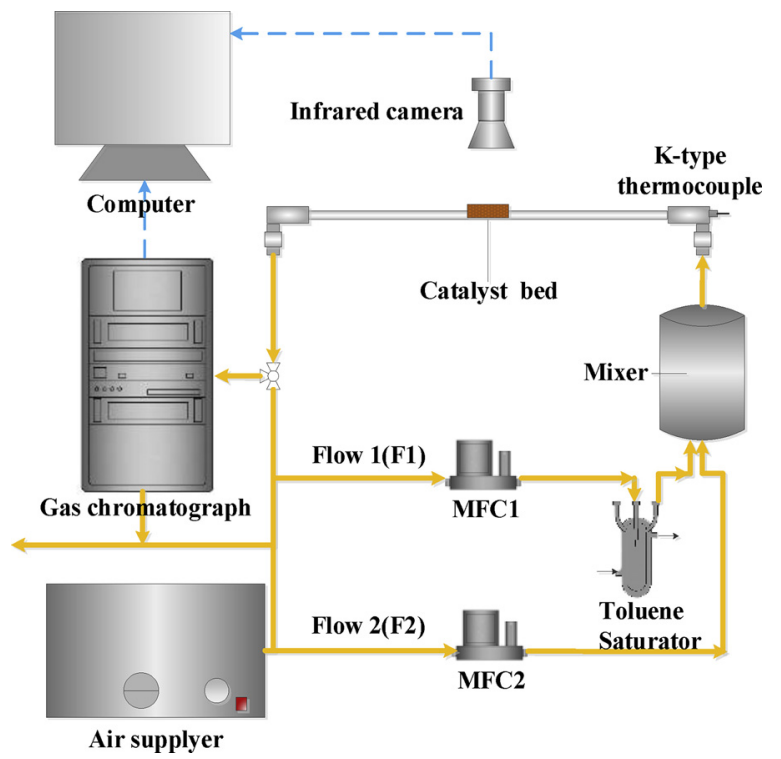

Fig. 1. Schematic of the experimental set-up for toluene self-sustained combustion. 


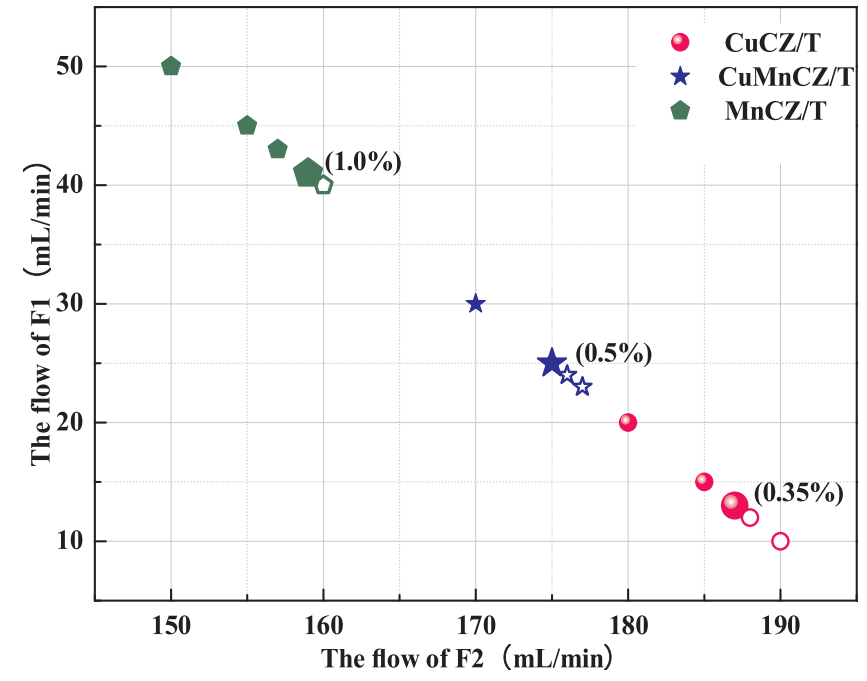

Fig. 2. Lean-combustion limits of toluene self-sustained combustion over $\mathrm{CuCZ} / \mathrm{T}, \mathrm{CuMnCZ} / \mathrm{T}$ and MnCZ/T catalystsc.

higher than the room temperature with a range of $\pm 2{ }^{\circ} \mathrm{C}$ in $10 \mathrm{~min}$. The activity of the catalyst can be estimated in terms of the lean-combustion limit (the lowest concentration required for toluene self-sustained combustion over the catalyst) in the combustion. Meanwhile, it can also be measured by the toluene conversion.

\section{Results and discussion}

3.1. Lean-combustion limits and catalytic activities of toluene self-sustained combustion

The lean-combustion limits with different catalysts for toluene selfsustained combustion in the micro-reactor were investigated by progressively decreasing the toluene concentration (described in Section 2.4) until the process was quenched, and the results are shown in Fig. 2. It can be seen from the figure that the lean-combustion limits over $\mathrm{CuCZ} / \mathrm{T}$, CuMnCZ/T and MnCZ/T are $0.35 \%, 0.50 \%$, and $1.00 \%$, respectively. The lean-combustion limit is in direct proportional to the
Table 1

The ignition, light-off and complete combustion of toluene catalytic combustion.

\begin{tabular}{|c|c|c|c|c|c|c|c|c|c|}
\hline \multirow[t]{3}{*}{ Catalyst } & \multicolumn{9}{|c|}{$\mathrm{C}_{7} \mathrm{H}_{8}$ concentration (\%) } \\
\hline & \multicolumn{3}{|l|}{0.35} & \multicolumn{3}{|c|}{0.50} & \multicolumn{3}{|c|}{1.00} \\
\hline & $T_{\mathrm{ig}}$ & $T_{\mathrm{lo}}$ & $T_{\text {co }}$ & $T_{\mathrm{ig}}$ & $T_{\mathrm{lo}}$ & $T_{\mathrm{co}}$ & $T_{\mathrm{ig}}$ & $T_{\mathrm{lo}}$ & $T_{\text {co }}$ \\
\hline CuCZT & 187 & 224 & 234 & 180 & 226 & 234 & 190 & 228 & 236 \\
\hline CuMnCZ/T & 196 & 228 & 238 & 184 & 230 & 238 & 216 & 233 & 243 \\
\hline $\mathrm{MnCZ} / \mathrm{T}$ & 230 & 273 & 284 & 229 & 276 & 288 & 237 & 285 & 296 \\
\hline
\end{tabular}

$\mathrm{T}_{\mathrm{ig}}$ : the ignition temperature required for $10 \%$ conversion of toluene at the heating process.

$\mathrm{T}_{\mathrm{lo}}$ : the light-off temperature which $50 \%$ toluene conversion is achieved at the heating process.

$\mathrm{T}_{\mathrm{co}}$ : the complete temperature that the conversion of toluene is $90 \%$ at the heating process.

catalyst activity $[4,5]$.

Fig. 3 illustrates the toluene conversion in the fixed bed with the different lean-combustion limit, and the corresponding $T_{\mathrm{ig}}, T_{\mathrm{lo}}$ and $T_{\mathrm{co}}$ are listed in Table 1. In Fig. 3(A), for instance, when the toluene concentration at 0.35 con. $\%, T_{\text {co }}$ of $\mathrm{CuCZ} / \mathrm{T}, \mathrm{CuMnCZ} / \mathrm{T}$ and $\mathrm{MnCZ} / \mathrm{T}$ catalysts are $234^{\circ} \mathrm{C}, 238^{\circ} \mathrm{C}$ and $284^{\circ} \mathrm{C}$, respectively. In addition, the heat lines of toluene conversion shift toward higher temperature with the increase of toluene concentration and manganese content in catalysts. It is worth noting that the toluene conversion over $\mathrm{CuCZ} / \mathrm{T}$ remains at $100 \%$ even if the temperature drops below $50{ }^{\circ} \mathrm{C}$ during the cooling process, which is evident that the heat released from reaction can maintain the stable combustion. Comparing the results of leancombustion limit with the $T_{\text {co }}$ of different catalysts, it is implied that the catalytic activity of $\mathrm{CuCZ} / \mathrm{T}$ is the best, with the decrease order of $\mathrm{CuCZ} / \mathrm{T}>\mathrm{CuMnCZ} / \mathrm{T}>\mathrm{MnCZ} / \mathrm{T}$. The phenomenon observed is different with Xin et al [9] in Introduction, and the synergistic effect between $\mathrm{Cu}$ and $\mathrm{Mn}$ species was failed to show in CuMnCZ/T catalyst used in this work. A possible reason for better activity of $\mathrm{CuCZ} / \mathrm{T}$ is due to the strong interaction between copper oxide and titanium dioxide. Highly dispersed copper oxide is converted to low-valent copper ions by $\mathrm{Cu}^{2+}+\mathrm{Ti}^{3+} \rightarrow \mathrm{Cu}^{+}+\mathrm{Ti}^{4+}$. The existence of $\mathrm{Cu}^{+}$could be more beneficial for surface adsorbed oxide ion to trap electrons through the following process: $\mathrm{Cu}^{+}+\mathrm{O}_{\mathrm{ads}} \rightarrow \mathrm{O}_{\mathrm{ads}}{ }^{-}+\mathrm{Cu}^{2+}$, which promotes the

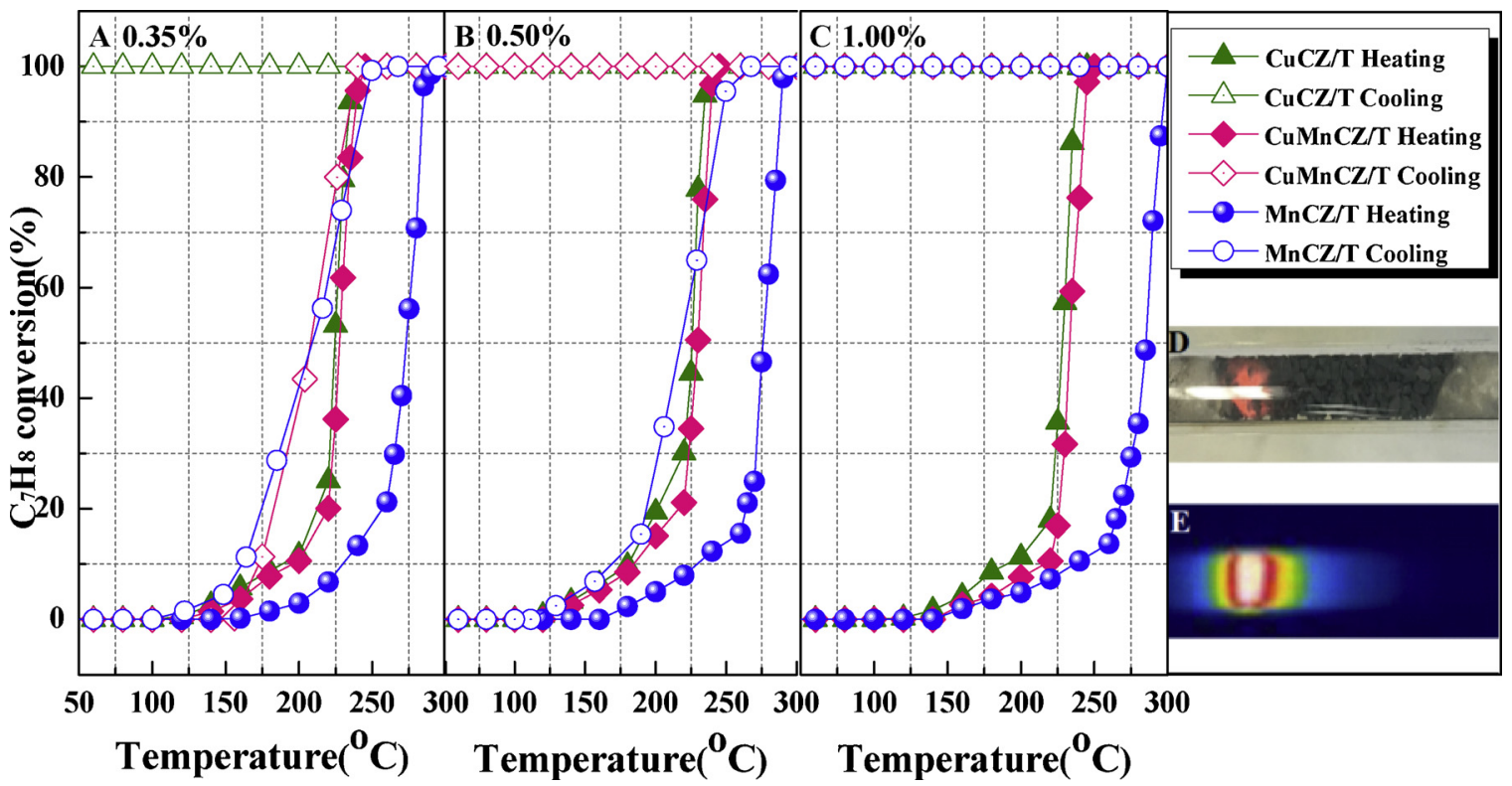

Fig. 3. Activity of toluene catalytic combustion with different lean-combustion limit of 0.35 con. \% (A), 0.50 con. $\%$ (B), 1.00 con. \% (C) and the recorded combustion image (D) and the corresponding temperature distribution (E). 


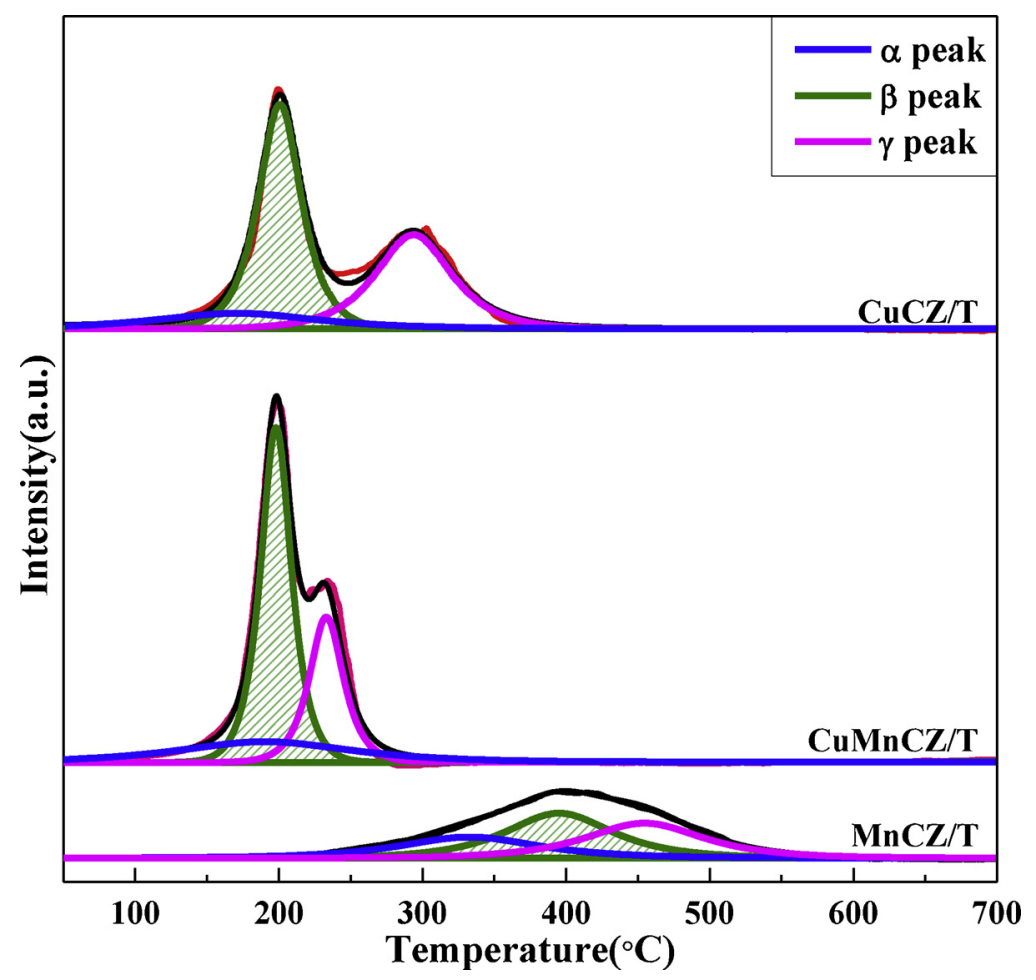

Fig. 4. $\mathrm{H}_{2}$-TPR patterns of CuCZ/T, CuMnCZ/T and MnCZ/T catalysts.

Table 2

The relative intensity of the reduction peaks on the $\mathrm{H}_{2}$-TPR curves.

\begin{tabular}{llllll}
\hline Catalysts & \multicolumn{5}{l}{$\mathrm{H}_{2}$ consumptions $\left(\mu \mathrm{mol} \cdot \mathrm{g}^{-1}\right)$} \\
\cline { 3 - 6 } & $\alpha$ peak & $\beta$ peak & $\gamma$ peak & Total & $\mathrm{R}_{\mathrm{d}}(\%)$ \\
\hline $\mathrm{CuCZ} / \mathrm{T}$ & $25.7 \pm 0.4$ & $98.2 \pm 0.8$ & $70.6 \pm 0.5$ & $194.5 \pm 1.7$ & 38.9 \\
$\mathrm{CuMnCZ} / \mathrm{T}$ & $36.5 \pm 0.5$ & $104.5 \pm 0.9$ & $50.3 \pm 0.6$ & $191.3 \pm 2.0$ & 53.1 \\
$\mathrm{MnCZ} / \mathrm{T}$ & $29.3 \pm 0.4$ & $45.9 \pm 0.6$ & $41.5 \pm 0.6$ & $116.7 \pm 1.6$ & 41.4
\end{tabular}

*The degree of the uncertainty was calculated by equations (1) in the supporting information.

formation of radicals with strong oxidizing properties, resulting in an improvement of the activity of the catalyst [18]. Another reason might be that there was low content of $\mathrm{CuMnO}_{\mathrm{x}}(4 \%)$ in the process of catalyst preparation, and $\mathrm{CuO}_{\mathrm{x}}$ species are prior to form the $\mathrm{Cu}-\mathrm{Ce}-\mathrm{Zr}-\mathrm{O}$ solid solution with $\mathrm{Ce}$ and $\mathrm{Zr}$ species detected by $\mathrm{H}_{2}$-TPR, thus limiting the $\mathrm{Mn}$ species interacting with $\mathrm{CuO}_{\mathrm{x}}$ to form the $\mathrm{Cu}-\mathrm{Mn}$ spinel.

In the toluene self-sustained catalytic combustion, the continuous combustion can be achieved by the heat released from the reaction, and no external heating is required. The catalyst with lower activity needs higher toluene concentration for affording higher ignition temperature and achieving intense exothermic reaction rapidly. Take $\mathrm{CuCZ} / \mathrm{T}$ for instance (Fig. 3A), the heating process of catalytic self-sustained combustion can be divided into three steps. The first step is described as an induction process with which the toluene conversion increases slowly at a lower temperature $\left(<T_{\mathrm{ig}}=187^{\circ} \mathrm{C}\right)$. Here, the consumed reactants can be quickly supplemented by the internal diffusion, as embodied in the temperature of the catalyst bed near the setting temperature. When the sufficient power is generated from reaction exothermicity in comparison to the heat dissipation in the process, the toluene conversion is fast enough to ignite, occurring at local hot points of catalyst surface. The accumulation of heat induces a steep increase of the local temperature and reactant rates, then the flame spreads rapidly in the catalyst bed to enter the second step - - transient light-off period $\left(<T_{\mathrm{ig}}-T_{\mathrm{lo}}\left(224^{\circ} \mathrm{C}\right)\right)$. Here toluene oxidation rate is increasing to lead a thermochemical runaway reaction, which consequently expedites the external diffusion and mass transfer. In the third step (self-sustained combustion stage), the combustion reaction rate is mainly controlled by the toluene and $\mathrm{O}_{2}$ diffusion rather than temperature on the catalyst surface [19]. In cooling process, the heat transfer between the surrounding and the wall of the combustion reactor is based mainly on radiation heat transfer, and the nature convection is minor. The lower lean-combustion limit of toluene over $\mathrm{CuCZ} / \mathrm{T}$ catalyst, which generates less heat in exothermic reaction, is favorable to minimize the temperature gradient between the reactor wall and the surroundings. Consequently, it can allow the stability of micro-combustion based on the heat accumulated by the reaction.

\subsection{Catalyst characterization}

\subsubsection{XRD analysis of catalysts}

The XRD patterns of CuCZ/T, CMCZ/T and MnCZ/T catalysts were shown in Fig. S1 (supporting information). All the reflections exhibited in the samples are in agreement with the typical diffraction patterns of $\mathrm{TiO}_{2}$ (P25). No additional peaks were observed in the patterns indicating that the presence of highly dispersed species of metal oxides supported on $\mathrm{TiO}_{2}$ or the possible formation of amorphous or nanocrystalline of metals which are too small to be detected by XRD. Therefore it could not be deduced with the cell parameters. There, the content of $\mathrm{Cu}_{\mathrm{x}} \mathrm{Mn}_{1-\mathrm{x}} \mathrm{O}_{2-\delta}, \mathrm{CeO}_{2}$ and $\mathrm{ZrO}_{2}$, which were calculated before the preparation of the catalysts, are $4.0 \%, 8.1 \%$ and $5.8 \%$, respectively.

\subsection{2. $\mathrm{H}_{2}$-TPR analysis of catalysts}

The redox properties of $\mathrm{CuCZ} / \mathrm{T}, \mathrm{CuMnCZ} / \mathrm{T}$ and $\mathrm{MnCZ} / \mathrm{T}$ catalysts investigated by $\mathrm{H}_{2}$-TPR are displayed in Fig. 4 (The TPR patterns of pure $\mathrm{CuO}, \mathrm{MnO}_{2}$ and $\mathrm{CeZrO}_{\mathrm{x}}$ are presented in Fig. S2). In Fig. S2, the reduction of pure $\mathrm{CuO}$ is observed at $150-350^{\circ} \mathrm{C}$ and characterized by two overlapping peaks at 240 and $264^{\circ} \mathrm{C}$. The peak at lower temperature is attributed to the reduction of highly dispersed $\mathrm{CuO}_{\mathrm{x}}$ on the surface of catalyst, including the isolated $\mathrm{Cu}^{2+}$ and the small-scale copper clusters with two dimensions and three dimensions structures. And another peak represents the reduction of $\mathrm{Cu}^{+}$species [20]. For 


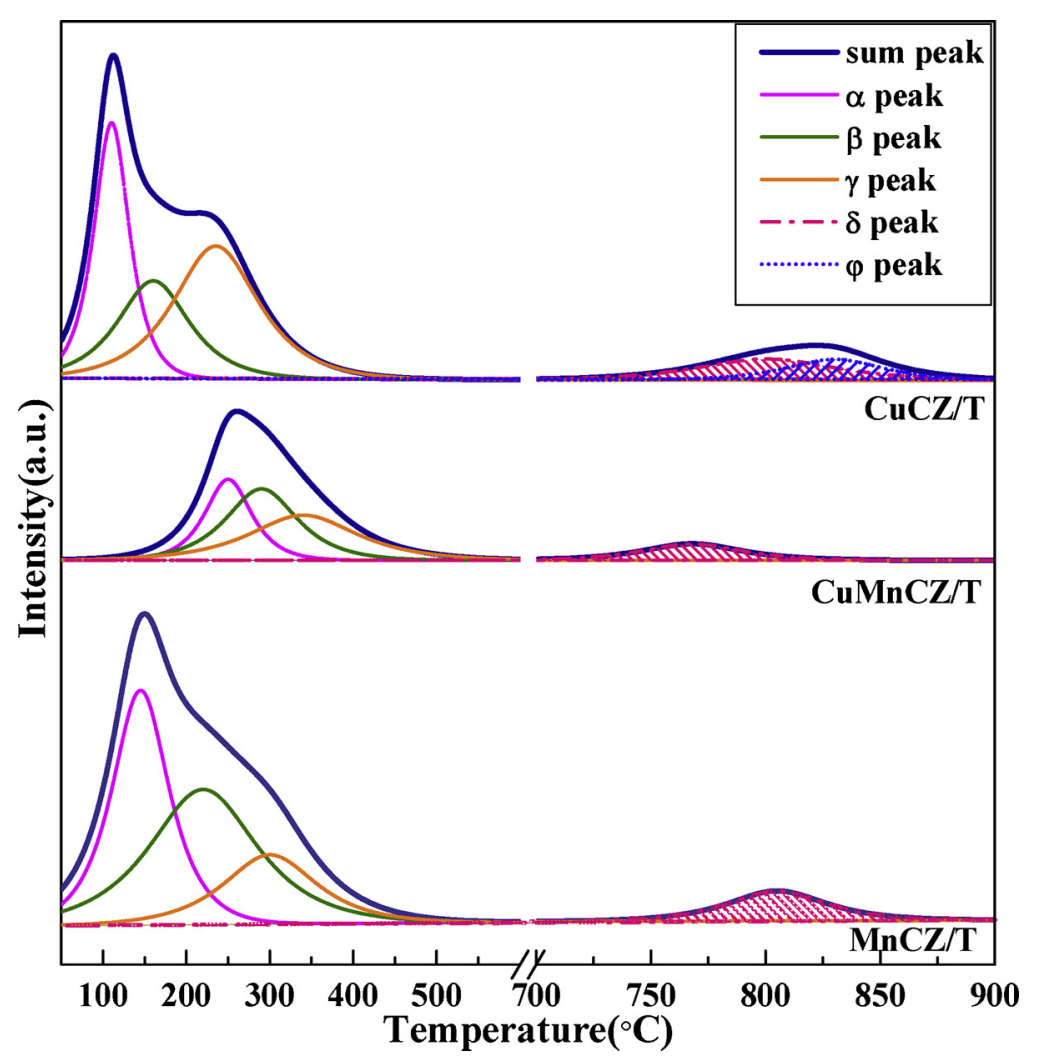

Fig. 5. $\mathrm{O}_{2}$-TPD patterns of CuCZ/T, CuMnCZ/T and MnCZ/T catalysts.

Table 3

The relative intensity of the desorption peaks on the $\mathrm{O}_{2}$-TPD curves.

\begin{tabular}{|c|c|c|c|c|c|}
\hline \multirow[t]{3}{*}{ catalysts } & \multicolumn{5}{|c|}{$\mathrm{O}_{2}$ consumption $\left(\mu \mathrm{mol} \cdot \mathrm{g}^{-1}\right)$} \\
\hline & \multicolumn{3}{|c|}{ adsorbed oxygen } & \multicolumn{2}{|c|}{ surface lattice } \\
\hline & $\alpha$ peak & $\beta$ peak & $\gamma$ peak & $\delta$ peak & $\varphi$ peak \\
\hline $\mathrm{CuCZ} / \mathrm{T}$ & $8.0 \pm 0.3$ & $6.0 \pm 0.2$ & $10 \pm 0.4$ & $1.0 \pm 0.4$ & $0.7 \pm 0.4$ \\
\hline CuMnCZ/T & $4.0 \pm 0.1$ & $5.0 \pm 0.2$ & $1.0 \pm 0.2$ & $0.5 \pm 0.2$ & - \\
\hline $\mathrm{MnCZ} / \mathrm{T}$ & $12 \pm 0.4$ & $13 \pm 0.4$ & $6.0 \pm 0.2$ & $1.0 \pm 0.2$ & - \\
\hline
\end{tabular}

pure $\mathrm{MnO}_{2}$, there is only a broad hydrogen consumption below $500{ }^{\circ} \mathrm{C}$ related to the reduction of $\mathrm{MnO}_{2}$. The hydrogen consumption of $\mathrm{CeZrO}_{\mathrm{x}}$ are shown a single reduction peak at $400-700{ }^{\circ} \mathrm{C}$ attributed to the partial reduction of $\mathrm{Ce}^{4+}$ to $\mathrm{Ce}^{3+}$ at the surface and bulk of the Ce-Zr-O solid solution [21], is not detected in the TPR profiles of catalysts (Fig. 4).

As shown in Fig. 4, the reduction peaks for all the catalysts can be divided into three peaks, labeled as $\alpha, \beta$ and $\gamma$. The reduction of $\mathrm{CuO}$ in $\mathrm{CuCZ} / \mathrm{T}$ catalyst takes place at the lower temperature than the pure $\mathrm{CuO}$ species, including the main peak $(\beta)$ at the range of $150-270{ }^{\circ} \mathrm{C}$ and a smaller peak $(\gamma)$ at $200-400{ }^{\circ} \mathrm{C}$. The addition peak $(\alpha)$ at the lowest temperature about $170^{\circ} \mathrm{C}$ can be ascribed to the reduction of the $\mathrm{CuO}_{\mathrm{x}}$ species that interact with ceria [13]. The dispersed $\mathrm{CuO}_{\mathrm{x}}$ species could incorporate into the cubic vacant sites of ceria and form a fivecoordinated surface structure with the capping oxygen, and this unsteady structure can promote the reduction of the $\mathrm{CuO}_{\mathrm{x}}$ species and the surface oxygen [22]. For CuMnCZ/T catalyst, the attributions of three peaks are similar to that of $\mathrm{CuCZ} / \mathrm{T}$, including the $\alpha$ peak $\left(50-350{ }^{\circ} \mathrm{C}\right), \beta$ peak $\left(150-250^{\circ} \mathrm{C}\right)$ and $\gamma$ peak $\left(200-300^{\circ} \mathrm{C}\right)$. According to the literature, it is attributes to the reduction of the $\mathrm{CuO}_{\mathrm{x}}$ and $\mathrm{MnO}_{\mathrm{x}}$ [20]. But it is difficult to distinguish the peak corresponding to copper or manganese species because the peaks were overlapping with each other. However, $\mathrm{MnCZ} / \mathrm{T}$ is reduced difficultly in comparation with other catalysts because of its low free energy to form the $\mathrm{MnO}_{\mathrm{x}}$ [13]. The three peaks observed for $\mathrm{MnCZ} / \mathrm{T}$ at $300-500{ }^{\circ} \mathrm{C}$ is similar to the pure $\mathrm{MnO}_{2}$. It is divided into the three peaks, labeled $\alpha\left(200-400{ }^{\circ} \mathrm{C}\right), \beta\left(250-500{ }^{\circ} \mathrm{C}\right)$ and $\gamma\left(300-550^{\circ} \mathrm{C}\right)$, are related to the reductions of $\mathrm{MnO}_{2}, \mathrm{Mn}_{2} \mathrm{O}_{3}$ and the $\mathrm{Mn}_{3} \mathrm{O}_{4}$, respectively [12].

The corresponding $\mathrm{H}_{2}$ consumptions and the $\mathrm{R}_{d}$ of $\mathrm{CuMnO}_{\mathrm{x}}$ are listed in Table 2. It is suggested that the reduction of $\mathrm{Mn}^{4+} \rightarrow \mathrm{Mn}^{3+}$ might occur at the lower temperature to increase the $\mathrm{H}_{2}$ consumption of $\beta$ peak in CuMnCZ/T catalyst [22]. Addition of $\mathrm{Mn}$ to $\mathrm{CuCZ} / \mathrm{T}$ slightly modified the redox ability of catalyst and promoted the reduction at lower temperature. That can be explained by the fact that an amount of $\mathrm{MnO}_{\mathrm{x}}$ doped with $\mathrm{CuO}$ can form the lattice defects and oxygen vacancies, and consequently enhance the transfer of oxygen species to promote each other's reduction ability [23]. The total hydrogen consumption of the CuMnCZ/T(191.3 $\left.\pm 2.0 \mu \mathrm{mol} \cdot \mathrm{g}^{-1}\right)$ is similar to that on the CuCZ/T(194.5 $\left.\pm 1.7 \mu \mathrm{mol} \cdot \mathrm{g}^{-1}\right)$, which are higher than that of $\mathrm{MnCZ} / \mathrm{T}\left(116.7 \pm 1.6 \mu \mathrm{mol} \cdot \mathrm{g}^{-1}\right)$. The reason probably is due to that the more content of easier reduction $\mathrm{Mn}^{4+}$ ions of CuMnCZ/T catalyst in comparison with MnCZ/T [24], which were detected by XPS. It is also consistent with the performance of catalytic activity to some extent.

From the Table 2, the results showed that the $\mathrm{R}_{\mathrm{d}}$ of catalysts with the decrease order of CuMnCZ/T (53.1\%) > MnCZ/T (41.4\%) > CuCZ/T (38.9\%). In this work, the $\mathrm{T}_{\mathrm{ig}}$ and $\mathrm{T}_{\text {co }}$ of toluene self-sustained combustion are below $300{ }^{\circ} \mathrm{C}$. However, manganese starts to be reduced when the temperature is higher than $300{ }^{\circ} \mathrm{C}$. Probably it is the main reason that catalysts with manganese has the higher reduction degree and the lower activity. Hence, the catalytic activity is mainly related to the reduction temperature of catalysts, and is little affected by the reduction degree.

\subsection{3. $\mathrm{O}_{2}-\mathrm{TPD}$ spectra of the catalysts}

The $\mathrm{O}_{2}$-TPD profiles of the CuCZ/T, CuMnCZ/T and MnCZ/T samples are shown in Fig. 5, and the relative intensity of the desorption 

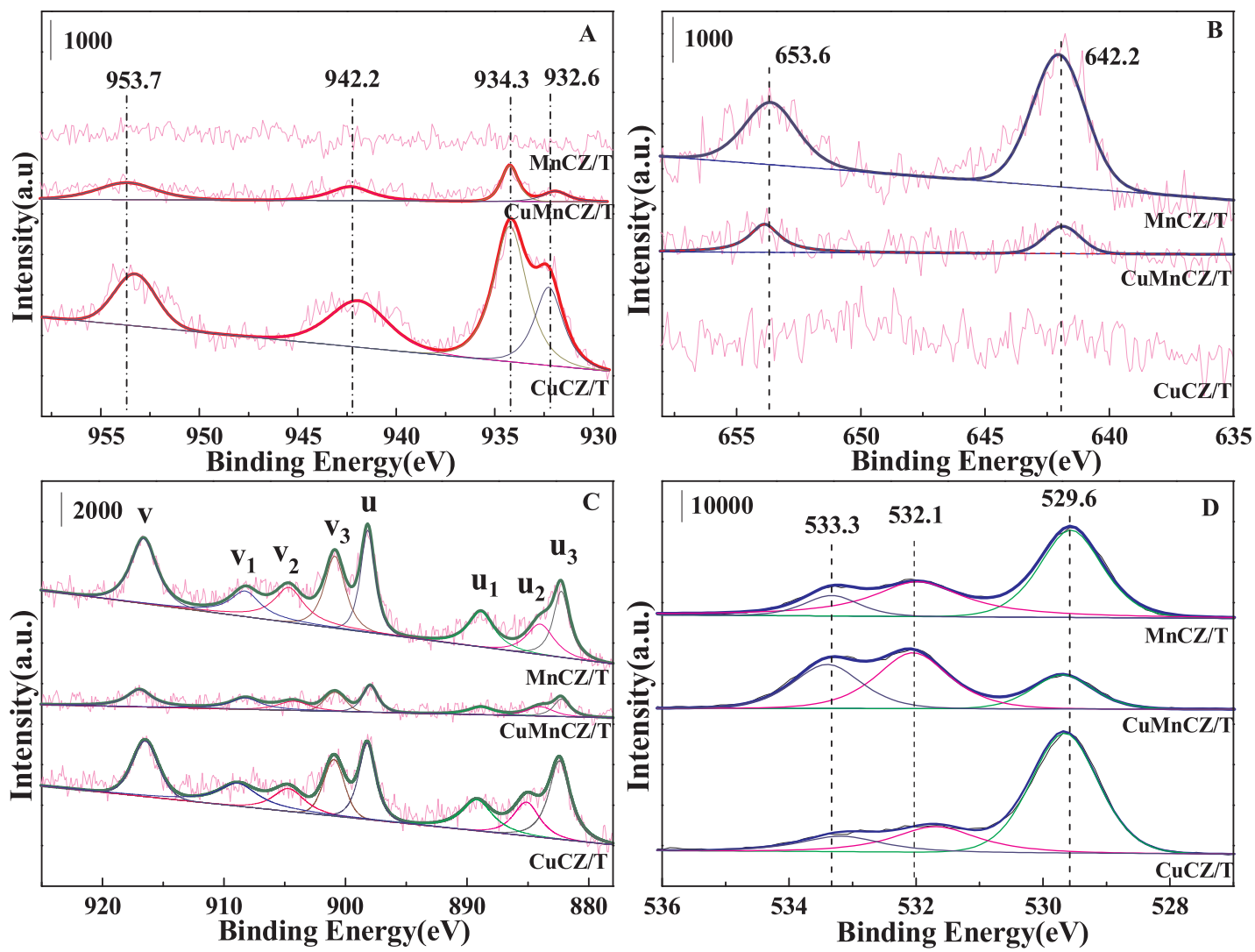

Fig. 6. XPS patterns of $\mathrm{Cu} 2 \mathrm{p}(\mathrm{A}), \mathrm{Mn} 2 \mathrm{p}(\mathrm{B})$, Ce $3 \mathrm{~d}(\mathrm{C})$, and $\mathrm{O} 1 \mathrm{~s}$ (D) for CuCZ/T, CuMnCZ/T and MnCZ/T catalysts.

Table 4

The surface species of CuCZ/T, CuMnCZ/T and MnCZ/T catalysts.

\begin{tabular}{|c|c|c|c|c|c|c|}
\hline \multirow[t]{2}{*}{ Caralyst } & \multirow[t]{2}{*}{$(\mathrm{Cu}+\mathrm{Mn}) / \mathrm{Ti} \%$} & \multirow[t]{2}{*}{$\mathrm{Cu}^{+} / \mathrm{Cu}^{2+}$} & \multirow[t]{2}{*}{$\mathrm{Ce}^{3+} / \mathrm{Ce}^{4+}$} & \multicolumn{3}{|c|}{ Oxygen Species (\%) } \\
\hline & & & & $\mathrm{O}_{\mathrm{ad}}$ & $\mathrm{O}_{\mathrm{la}}$ & $\mathrm{O}_{\mathrm{la}} / \mathrm{O}_{\text {to }}$ \\
\hline $\mathrm{CuCZ} / \mathrm{T}$ & $2.00 \pm 0.06$ & $0.31 \pm 0.02$ & $0.35 \pm 0.02$ & $11 \pm 1$ & $76 \pm 2$ & $87.36 \pm 0.10$ \\
\hline $\mathrm{CuMnCZ/T}$ & $2.58 \pm 0.07$ & $0.26 \pm 0.01$ & $0.31 \pm 0.02$ & $32 \pm 1$ & $67 \pm 1$ & $67.67 \pm 0.33$ \\
\hline $\mathrm{MnCZ} / \mathrm{T}$ & $1.60 \pm 0.09$ & - & $0.25 \pm 0.01$ & $14 \pm 1$ & $85 \pm 2$ & $85.54 \pm 0.27$ \\
\hline
\end{tabular}

Ola $=$ Ola,r + Ola,, Oto $=$ Oad + Ola $=99 \%$

peaks on the $\mathrm{O}_{2}$-TPD curves are listed in Table 3. The catalysts exhibit similar spectra and can be distinguishably classified into two types of oxygen species, namely, the adsorbed oxygen located at surface vacancies below $550{ }^{\circ} \mathrm{C}$ and the surface lattice oxygen at the higher temperature between $700{ }^{\circ} \mathrm{C}$ and $900{ }^{\circ} \mathrm{C}$. The first broad peak can be divided into three characteristic peaks (denoted as $\alpha, \beta$ and $\gamma$ peak) differentiated by the strength of the catalyst surface, which are attributed to the weakly adsorbed oxygen species, $\mathrm{O}_{2}{ }^{-}$and $\mathrm{O}^{-}$species formed by the adsorbed $\mathrm{O}_{2}$ [25]. The $\delta$ and $\varphi$ peaks are assigned to lattice oxygen species $\left(\mathrm{O}^{2-}\right)$ [26]. The lattice oxygen is considered as a major participator in deep oxidation of toluene, which is deeply discussed in Section 3.3. Compared with CuMnCZ/T $\left(0.5 \mu \mathrm{mol} \mathrm{g}^{-1}\right)$ and $\mathrm{MnCZ} / \mathrm{T}\left(1.0 \mu \mathrm{mol} \mathrm{g}^{-1}\right), \mathrm{CuCZ} / \mathrm{T}$ has the highest content of lattice oxygen $\left(1.7 \mu \mathrm{mol} \mathrm{g}^{-1}\right)$, indicating a largest amount of active oxygen centers for the catalyst. The higher concentration of $\mathrm{Ce}^{3+}$ of $\mathrm{CuCZ} / \mathrm{T}$ catalyst, which was detected by XPS, can promote the migration of the lattice oxygen from the bulk to the surface of catalyst. Sequentially, more active oxygen centers to facilitate the mobility of the lattice oxygen [25]. Obviously, the desorption peak of $\delta$ for CuMnCZ/T shifts slightly to lower region in comparison with CuCZ/T and MnCZ/T. The phenomenon can be explained by the fact that the presence of the appropriate amount of $\mathrm{Mn}$ enhances the formation of Cu-Mn-Ce-O ternary oxide solid solution with fluorite structure, thereby strengthens the capacity of the active center of oxygen [21].

\subsubsection{XPS measurements}

XPS is used to characterize the $\mathrm{Cu}, \mathrm{Mn}, \mathrm{Ce}$ and $\mathrm{O}$ oxidation state for $\mathrm{CuCZ} / \mathrm{T}, \mathrm{CuMnCZ} / \mathrm{T}$ and $\mathrm{MnCZ} / \mathrm{T}$ catalysts, and the results are depicted in Fig.6. The $\mathrm{Cu} 2 \mathrm{p}$ spectrum for the catalysts represents two main peaks of $\mathrm{Cu} 2 \mathrm{p}_{3 / 2}(933.6 \mathrm{eV})$ and $\mathrm{Cu} 2 \mathrm{p}_{1 / 2}(953.7 \mathrm{eV})$ in Fig. 6A. After the peak deconvolution, the coexistence of $\mathrm{Cu}^{+} / \mathrm{Cu}_{2} \mathrm{O}$ and $\mathrm{Cu}^{2+} / \mathrm{CuO}$ are well evidenced by the main peaks at $932.6 \mathrm{eV}$ with a shoulder peak observed at $934.3 \mathrm{eV}$. The shake-up satellites of $\mathrm{Cu}$ at about $942.2 \mathrm{eV}$ are assigned to the divalent copper [27]. The Mn 2p spectra exhibits two contributions of $\mathrm{Mn} 2 \mathrm{p}_{3 / 2}$ and $\mathrm{Mn} 2 \mathrm{p}_{1 / 2}$ located at $642.2 \mathrm{eV}$ and $653.6 \mathrm{eV}$ in Fig. 5B, corresponding to $\mathrm{Mn}^{3+}$ and $\mathrm{Mn}^{4+}$ ions, respectively [12].

In Fig. $6 \mathrm{C}$, the Ce $3 \mathrm{~d}$ spectra is distinguished into $\mathrm{Ce} 3 \mathrm{~d}_{5 / 2}$ and $\mathrm{Ce}$ $3 \mathrm{~d}_{3 / 2}$ (labeled as $\mathrm{u}$ and $\mathrm{v}$, respectively) performing the $\mathrm{Ce}^{3+} / \mathrm{Ce}^{4+}$ electron-pair. The four intense peaks at $\mathrm{u}(898.1 \mathrm{eV}), \mathrm{v}(916.6 \mathrm{eV}), \mathrm{u}_{3}$ $(882.3 \mathrm{eV})$ and $\mathrm{v}_{3}(900.9 \mathrm{eV})$ with the two weak peaks at $\mathrm{u}_{1}(888.9 \mathrm{eV})$ and $\mathrm{v}_{1}(908.3 \mathrm{eV})$, can be attributed to the different $\mathrm{Ce} 4 \mathrm{f}$ electron configurations in the final states of the $\mathrm{Ce}^{4+}$ species. The $\mathrm{u}_{2}$ and $\mathrm{v}_{2}$ peaks presented at $904.7 \mathrm{eV}$ and $884.1 \mathrm{eV}$ belong to the $\mathrm{Ce}^{3+}$ species 




Fig. 7. The in-situ DRIFT spectra of toluene oxidation over CuCZ/T catalyst. (A) The wavenumber range of $1000 \sim 4000 \mathrm{~cm}^{-1}$. (B) The wavenumber range of $1000 \sim 2000 \mathrm{~cm}^{-1}$.

[16], which is due to the entrance of copper/manganese ions into the $\mathrm{CeO}_{2}$ lattice causing lattice imperfection and generating trivalent cerium ions [27].

The $\mathrm{O} 1 \mathrm{~s}$ spectra of the three catalysts is clearly resolved into three peaks by deconvolution (Fig. 6D), proving the presence of three chemical environments for oxygen atoms. The value of $529.6 \mathrm{eV}$ is generally accepted as being a feature of the characteristic lattice oxygen $\left(\mathrm{O}_{\mathrm{la}, \mathrm{m}}\right)$ bonded to copper, manganese, cerium and zirconium cations. The second one at higher binding energies $(532.1 \mathrm{eV})$, with lower intensity, is the characteristic of the regular lattice oxygen $\left(\mathrm{O}_{\mathrm{la}, \mathrm{t}}\right)$ of $\mathrm{TiO}_{2}$, and the shoulder peak at $533.3 \mathrm{eV}$ indicates the presence of chemisorbed oxygen $\left(\mathrm{O}_{\mathrm{ad}}\right)$ [27].

The related description for the XPS data is listed in Table 4 , including the surface species of $(\mathrm{Cu}+\mathrm{Mn}) / \mathrm{Ti}, \mathrm{Cu}^{+} / \mathrm{Cu}^{2+}, \mathrm{Ce}^{3+} / \mathrm{Ce}^{4+}$ and atomic ratio of the $\mathrm{CuCZ} / \mathrm{T}, \mathrm{CuMnCZ} / \mathrm{T}$ and $\mathrm{MnCZ} / \mathrm{T}$ catalysts. It is observed that the contents of $(\mathrm{Cu}+\mathrm{Mn}) / \mathrm{Ti}$ for the obtained catalysts are less than the theoretical value (loading $4.0 \mathrm{wt} \%$ ), which confirms that the $\mathrm{Cu}$ and/or $\mathrm{Mn}$ ions are introduced into $\mathrm{CeO}_{2}-\mathrm{ZrO}_{2}$ lattice and the lattice imperfections are formed. The higher $\mathrm{Cu}^{+} / \mathrm{Cu}^{2+}$ ratio in CuCZ/T (0.31) compared to CuMnCZ/T (0.26) provides the evidence of the interaction between divalent copper ions and titanium ions. Consequently, the cerium species with lower oxidation states via the redox equilibrium of $\mathrm{Cu}^{+}+\mathrm{Ce}^{4+} \leftrightarrow \mathrm{Cu}^{2+}+\mathrm{Ce}^{3+}[5,28]$, improve the ratio of $\mathrm{Ce}^{3+} / \mathrm{Ce}^{4+}(0.35)$ in $\mathrm{CuCZ} / \mathrm{T}$, which is higher than that in CuMnCZ/T (0.31). The presence of more $\mathrm{Cu}^{+}$species in the catalysts can promote the catalytic performance for the oxidation reaction. The replacement of $\mathrm{Ce}^{4+}$ from $\mathrm{Ce}^{3+}$ can form the defect structure, resulting in the oxygen vacancies and unsaturated chemical bonds on the catalyst surface, and bringing the transfer of more chemisorbed oxygen species in ceria into lattice oxides for charge balance [28]. $\mathrm{O}_{1 a}$ species is the main participator in the process of toluene oxidation according to MVK reaction mechanism. Consequently, the highest $\mathrm{O}_{\mathrm{la}}$ ratio is up to $87.36 \%$ in $\mathrm{CuCZ} / \mathrm{T}$ compared with $67.67 \%$ in $\mathrm{CuMnCZ} / \mathrm{T}$ catalyst, indicating the lattice oxygen species relative concentration increases with the content of copper. The result is confirmed by $\mathrm{O}_{2}$-TPD.

\subsection{Reaction pathway of toluene catalytic combustion}

The catalytic combustion of toluene can generate some intermediate products before complete oxidation into $\mathrm{CO}_{2}$ and $\mathrm{H}_{2} \mathrm{O}$. In our previous work, the analysis of intermediate species combined with the Mars-van Krevelen (MVK) mechanism could explain the oxidation performances of ethyl acetate and toluene on CuCZ/T catalyst to some extent [17]. However, the specific reaction pathways including the adsorption and oxidation of toluene are still not clear.

In this study, the in-situ DRIFT was used to further analyse the reaction process of toluene catalytic combustion over the $\mathrm{CuCZ} / \mathrm{T}$ catalyst, and the results are shown in Fig. 7. The samples were saturated under the toluene-oxygen atmosphere at the room temperature, until the changeless intensity of the characteristic IR bands associated with toluene, including the bands at $3100-2800 \mathrm{~cm}^{-1}$ (the stretching vibration of $\mathrm{C}-\mathrm{H}$ groups), and the bands at $1610-1380 \mathrm{~cm}^{-1}$ (the typical aromatic ring vibration) [29]. It is worth noting that the bands at 2934 and $2886 \mathrm{~cm}^{-1}$ are assigned to the methylene rather than methyl, because the symmetric and asymmetric $\mathrm{C}-\mathrm{H}$ stretching vibration of the $\mathrm{CH}_{3}$ group is usually observed in the $2970-2950 \mathrm{~cm}^{-1}$ region [10]. The appearance of weak bands at 1153 and $1082 \mathrm{~cm}^{-1}$ are probably

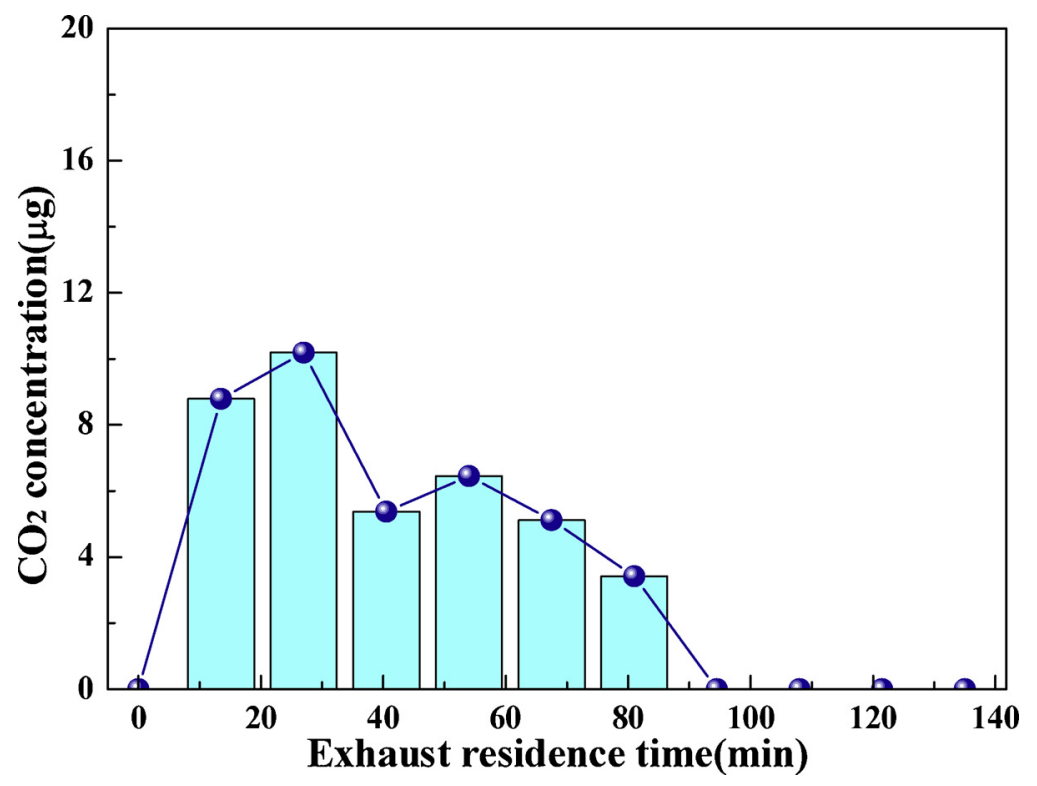

Fig. 8. The toluene combuston over CuCZ/T catalyst in $\mathrm{N}_{2}\left(160^{\circ} \mathrm{C}\right)$. 


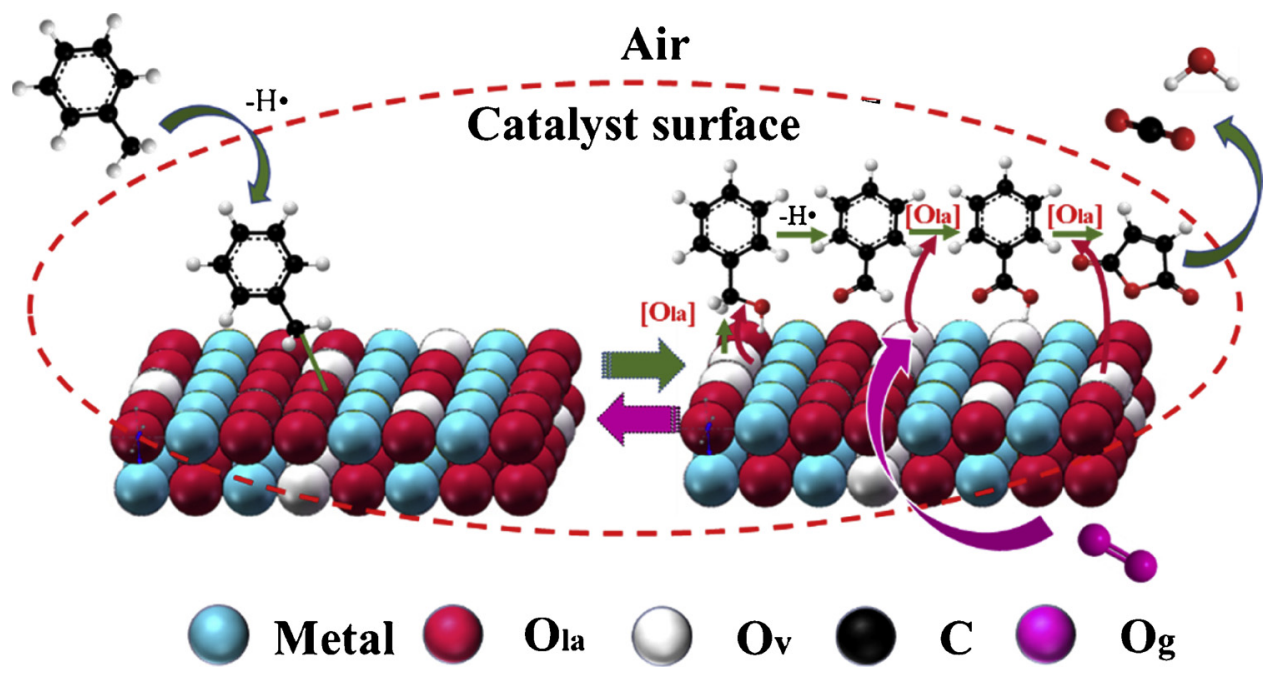

Fig. 9. The reaction pathway of toluene combustion.

ascribed to a $\mathrm{C}-\mathrm{O}$ vibration mode [10]. These results suggest that toluene is adsorbed on the CuCZ/T surface via the cleavage of the $\alpha-\mathrm{H}$ bond in the methyl group of toluene to form the benzyl species, which are subsequently combined with the active oxygen on the catalyst surface through the formation of benzoyl oxide species $\left(\mathrm{C}_{6} \mathrm{H}_{5}-\mathrm{CH}_{2}-\mathrm{O}\right)$ $[10,30]$. In addition, the positions of these bands do not shift to lower frequency compared with the spectra of liquid- or gaseous toluene. This phenomenon also testifies that the toluene is adsorbed on CuCZ/T surface via the $-\mathrm{CH}_{3}$ rather than the aromatic ring, because the interaction between the aromatic ring of toluene and the surface of $\mathrm{TiO}_{2}$ can lead to an obvious blue shift by forming $\pi$-complex [10]. The negative band at $3671 \mathrm{~cm}^{-1}$ and the band at $3593 \mathrm{~cm}^{-1}$ are caused by the surface hydroxyl group interacting with the methyl group of toluene [31], and it confirmsthe methyl group of toluene is adsorbed on catalyst once again.

Under low temperature conditions, hydroxyl groups adsorbed on the catalyst surface occupy the active sites, which hinders the futher oxidation of toluene. In Fig. 7A, it can be seen that when the band at $3593 \mathrm{~cm}^{-1}$ disappears, the signals of $\mathrm{CO}_{2}\left(2368\right.$ and $\left.2341 \mathrm{~cm}^{-1}\right)$ [5] increase rapidly with the decreasing of the toluene signals. In addition, the new bands appearing at 1301 and $1239 \mathrm{~cm}^{-1}$ (Fig. 6B) are attributed to the methylene group and the $\mathrm{C}-\mathrm{O}$ vibration mode of benzyl alcohol [29]. With the temperature increasing, the occurrence of the strong peaks at 1585,1518 and $1409 \mathrm{~cm}^{-1}$ resulting from the carboxylate group suggests the production of benzoic acid [32]. Furthermore, the weak bands at 1695 and $1648 \mathrm{~cm}^{-1}$ designated to aldehydic species are also tracked. And the weak bands at 1798 and $1737 \mathrm{~cm}^{-1}$ imply the appearance of anhydride species [25]. The band intensities of benzoic acid, aldehydic and anhydride species continuously increase with the increasing of temperature. Noticeably, with the reaction temperature higher than $350^{\circ} \mathrm{C}$, the intensities of $\mathrm{CO}_{2}$ bands are significantly higher than the others. According to the integral of the band areas at $400{ }^{\circ} \mathrm{C}$, the formation of $\mathrm{CO}_{2}$ has a approximately ratio of $98 \%$, which demonstrates that $\mathrm{CO}_{2}$ is the dominant product of toluene catalytic oxidation with traces of benzoic acid, aldehydic and anhydride species as by-products.

To investigate whether the lattice oxygen participates in the combustion of toluene or not, the experiment of the toluene combustion over CuCZ/T catalyst $(0.8 \mathrm{~g})$ at $160{ }^{\circ} \mathrm{C}$ (the temperature at which $\mathrm{CO}_{2}$ can be tracked firstly through GC) in $\mathrm{N}_{2}$ atmosphere was carried out, and the results are depicted in Fig. 8. The sample was first pretreated with $\mathrm{N}_{2}$ for $0.5 \mathrm{~h}$ at $400{ }^{\circ} \mathrm{C}$ to eliminate the effects of surface oxygen species. Although the reactants contain no gas-phase oxygen, $\mathrm{CO}_{2}$ was still detected by GC, which proves that lattice oxygen is in the involvement of the deep catalytic oxidation of toluene, in accordance with the previous result found by Sun et al. [10]. Furthermore, the amount of lattice oxygen consumed in the reaction by integral shows a good qualitative agreement with the peak area of lattice oxygen investigated by $\mathrm{O}_{2}$-TPD.

To sum up, combining with our previous study [17], the model established on the MVK reaction mechanism provides a good fit for the toluene combustion over $\mathrm{CuCZ} / \mathrm{T}$. Based on the redox process, there are two steps in the MVK model. Firstly, adsorbed toluene reacts with the lattice oxygen on the catalyst surface to produce the oxidation products, resulting in the reduction metal oxides. Secondaly, the reduced metal oxides are reoxidized by the gas phase oxygen. As schematically shown in Fig. 9, toluene is adsorbed on the active oxygen species on the catalyst surface, which occurs in the initiation by removing the $\alpha-\mathrm{H}$ of methyl to form the benzoyl oxide species $\left(\mathrm{C}_{6} \mathrm{H}_{5}-\mathrm{CH}_{2}-\mathrm{O}\right.$ ) (dark blue line), and then the reaction moves into subsequent oxidation steps (green line). Toluene is firstly converted to benzyl alcohol by lattice oxygen of the catalyst, then benzyl alcohol is further oxidized to benzoic acid, benzaldehyde and anhydride species on the surface of the catalyst, which are ultimately mineralized to $\mathrm{CO}_{2}$ and $\mathrm{H}_{2} \mathrm{O}$ to release into the atomsphere. In this case, the $\mathrm{CuCZ} / \mathrm{T}$ catalyst seems to be a reservoir of oxygen species to sustain oxidation, and the $\mathrm{Cu}-\mathrm{Ce}-\mathrm{O}_{2-\mathrm{x}}$ solid solution and $\mathrm{CeO}_{2}$ can provide the significant oxygen vacancy. The lattice oxygen species are consumed for the oxidation of toluene and form oxygen vacancy, which can be replenished easily by the gasphase oxygen activated on the catalyst surface (rose red line). This results can be explained by the coexistence of the mixed-valent $\mathrm{Cu}$ and the facile transform between $\mathrm{Cu}^{2+}$ and $\mathrm{Cu}^{+}$, as shown from XPS results. And the presence of coupled $\mathrm{Cu}^{2+} / \mathrm{Cu}^{+}$sites with $\mathrm{Ce}^{4+} / \mathrm{Ce}^{3+}$ sites can enhance the oxygen mobility throughout the bulk and the surface through electron exchange with cerium ions.

\section{Conclusions}

The catalytic self-sustained combustion of toluene over the CuCZ/ T、 CuMnCZ/T and MnCZ/T catalysts was investigated. The lean-combustion limits of toluene self-sustained combustion decrease with the improvement of the intrinsic catalyst activity. The results demonstrate that $\mathrm{CuCZ} / \mathrm{T}$ is more efficient than others for toluene self-sustained combustion based on the lower $T_{\mathrm{ig}}, T_{\mathrm{co}}$ and the lean-combustion limits. The performance enhancement of $\mathrm{CuCZ} / \mathrm{T}$ is probably attributed to the homogeneous morphology, the high redox properties and the strong oxygen storage/release ability, because of the greater quantities of monovalent copper ions and lattice oxygen.

In-situ DRIFT results indicate the reaction pathway of the toluene catalytic oxidation. The active oxygen species are the adsorption sites 
for the toluene oxidation. Toluene is adsorbed on the catalyst surface by abstracting a- $\mathrm{H}$ of the methyl group and forming benzoyl intermediates. These intermediates are oxidized successively into aldehydic, benzoate species, which are ultimately mineralized into $\mathrm{CO}_{2}$ and $\mathrm{H}_{2} \mathrm{O}$. by the lattice oxygen in the catalyst.

\section{Acknowledgments}

This work was accomplished under the support of National Nature Science Foundation of China (No 51776216) and Research Centre of Modern Analytic Technology in Tianjin University of Science \& Technology.

\section{Appendix A. Supplementary data}

Supplementary material related to this article can be found, in the online version, at doi:https://doi.org/10.1016/j.apcata.2018.10.034.

\section{References}

[1] S.C. Kim, W.G. Shim, Appl. Catal. B: Environ. 98 (2010) 180-185.

[2] W. Yang, Y. Wang, J. Zhou, Z. Wang, K. Cen, Chem. Eng. Sci. 158 (2017) 30-36.

[3] K. Bijjula, D.G. Vlachos, Proc. Combust. Inst. 33 (2011) 1801-1807.

[4] A. Scarpa, R. Pirone, G. Russo, D.G. Vlachos, Combust. Flame 156 (2009) 947-953.

[5] F. Bin, X. Wei, B. Li, K.S. Hui, Appl. Catal. B: Environ. 162 (2015) 282-288.

[6] F. Bin, X. Wei, T. Li, D. Liu, Q. Hao, B. Dou, Proc. Combust. Inst. 36 (2017) 4193-4200.

[7] Z. Huo, Transition Metal Oxides Nanostructures: Controlled Synthesis, Assembly and Their Properties, Tsinghua University, Beijing, 2009.

[8] N. Viswanadham, S.K. Saxena, A.H. Al-Muhtaseb, Mater. Today Chem. 3 (2017) $37-48$.
[9] U. Menon, V.V. Galvita, G.B. Marin, J. Catal. 283 (2011) 1-9.

[10] H. Sun, Z. Liu, S. Chen, X. Quan, Chem. Eng. J. 270 (2015) 58-65.

[11] P. Liu, H. He, G. Wei, D. Liu, X. Liang, T. Chen, J. Zhu, R. Zhu, Microporous Mesoporous Mater. 239 (2017) 101-110.

[12] X. Li, L. Wang, Q. Xia, Z. Liu, Z. Li, Catal. Commun. 14 (2011) 11-19.

[13] X. Guo, J. Li, R. Zhou, Fuel 163 (2016) 56-64.

[14] H.C. Genuino, S. Dharmarathna, E.C. Njagi, M.C. Mei, S.L. Suib, J. Phys. Chem. C 116 (2012) 969-976.

[15] Q. Yang, Q. Hao, N. Yan, R. Zhao, C. Zhao, Q. Zhang, B. Dou, F. Bin, J. Fuel Chem. Tech. 45 (2017) 1401-1408.

[16] S. Li, Q. Hao, R. Zhao, D. Liu, H. Duan, B. Dou, Chem. Eng. J. 285 (2016) 536-543.

[17] B. Dou, S. Li, D. Liu, R. Zhao, J. Liu, Q. Hao, F. Bin, RSC Adv. 6 (2016) 53852 538553859.

[18] S. Hao, Y. Yin, Z. Ma, Y. Qing, F. He, Xi. Qi, J. Hebei Univ. (Nat. Sci. Ed. 25 (05) (2005) 486-494.

[19] Y. Wang, Research on Carbon Monoxide Self-sustained Combustion Based on $\mathrm{CuCe}_{1}$ ${ }_{\mathrm{x}} \mathrm{Zr}_{\mathrm{x}} \mathrm{O}_{\mathrm{y}}$ Series Catalyst, Xi'an: Xi'an Jiaotong University, 2016.

[20] X. Guo, J. Li, R. Zhou, Fuel 163 (2016) 056-064.

[21] L. Li, F. Jing, J. Yan, J. Jing, W. Chu, Catal. Today 297 (2017) 167-172.

[22] L. Liu, Basic Research of Catalytic Reduction of Nn by The Catalytic Reduction of Copper Oxide Nano-Catalyst in Cerium and Zirconia, Nanjing university, Nanjing, 2010 .

[23] H. Lu, X. Kong, H. Huang, Y. Zhou, Y. Chen, J. Environ. Sci: China 32 (2015) $102-107$.

[24] F. Hu, J. Chen, S. Zhao, K. Si, H. Song, J. Li, Appl. Catal. A Gen. 540 (2017) 57-67.

[25] V.P. Santos, M.F.R. Pereira, J.J.M. Órfão, J.L. Figueiredo, Appl. Catal. B: Environ. 99 (2010) 353-363.

[26] C. Deng, Q. Huang, X. Zhu, Q. Hu, W. Su, J. Qian, L. Dong, B. Li, M. Fan, C. Liang, Appl. Surf. Sci. 389 (2016) 1033-1049.

[27] R. Kang, X. Wei, F. Bin, Z. Wang, Q. Hao, B. Dou, Appl. Catal. A Gen. (2018), https://doi.org/10.1016/j.apcata.2018.07.026.

[28] B. Dou, G. Lv, C. Wang, Q. Hao, K. Hui, Chem. Eng. J. 270 (2015) 549-556.

[29] J. Li, H. Na, X. Zeng, T. Zhu, Z. Liu, Appl. Surf. Sci. 311 (2014) 690-696.

[30] Y. Liu, H. Huang, X. Li, S. Sun, D. Zhao, J. Saf. Environ. 5 (2005) 14-16.

[31] F. Rainone, D.A. Bulushev, L.K. Minsker, A. Renken, Phys. Chem. Chem. Phys. 5 (2003) 4445-4449.

[32] S. Besselmann, E. Löffler, M. Muhler, J. Mol. Catal. A Chem. 162 (2000) 401-411. 